DOI: $10.2478 /$ lpts-2019-0030

\title{
MECHANISMS OF ELECTRON SCATTERING IN UNIAXIALLY DEFORMED SILICON SINGLE CRYSTALS WITH RADIATION DEFECTS
}

\author{
S.V. Luniov ${ }^{1}$, V.V. Lyshuk ${ }^{1}$, V.T. Maslyuk ${ }^{2}$, O.V. Burban ${ }^{3}$ \\ ${ }^{1}$ Lutsk National Technical University, 75 Lvivska Str., 43018 Lutsk, UKRAINE \\ ${ }^{2}$ Institute of Electron Physics NAS of Ukraine, 21 Universitetska Str., \\ Uzhghorod 88017, UKRAINE \\ ${ }^{3}$ Volyn College of the National University of Food Technologies, 6 Cathedral Str., \\ 43016 Lutsk, UKRAINE \\ e-mail: luniovser@ukr.net
}

\begin{abstract}
Temperature dependencies for Hall mobility of electrons for the uniaxially deformed $\mathrm{n}$-Si single crystals, irradiated by the flow of electrons $\Omega=1 \cdot 10^{17} \mathrm{el} . / \mathrm{cm}^{2}$ with the energy of $12 \mathrm{MeV}$, are obtained on the basis of piezo-Hall effect measurements. From the analysis of these dependencies it follows that under the uniaxial pressure (0-0.42) GPa and (0-0.37) GPa along crystallographic directions [100] and [111], respectively, the deformationinduced increase of the Hall mobility has been observed. On the basis of the proposed theoretical model of mobility, this increase is explained by the decrease of the amplitude of a large-scale potential with an increase in the magnitude of uniaxial deformation and, accordingly, the probability of electron scattering on this potential. The slight discrepancy between the obtained experimental results and the relevant theoretical calculations at the low temperatures is due to the fact that the electron scattering on the radiation defects, created by the electron radiation, was not taken into account in the calculations. The decrease in Hall mobility of electrons along with an increase in temperature for unirradiated and irradiated silicon single crystals is explained by the growth of the probability of electron scattering on the optical phonons that are responsible for the intervalley scattering in silicon. The obtained results can be used in designing and modelling on the basis of n-Si single crystals of various electronic devices of micro- and nanoelectronics, which can be subject to the extreme conditions of action of the significant radiation and deformation fields.
\end{abstract}

Keywords: hall mobility, large-scale potential, piezo-Hall effect, uniaxial deformation

\section{INTRODUCTION}

Monocrystalline silicon is a promising material for micro- and nanoelectronics thanks to the well-designed technology of its growing and relatively low cost [1]- 
[7]. It is known [7] that the traditional control of the electrical properties of silicon or other crystalline semiconductors is carried out by doping with various impurities that create in the band gap of semiconductor the discrete energy levels of the necessary depth and concentration. But often this method is difficult to implement due to the low solubility of the necessary impurities in semiconductors at higher concentrations of the electrically active intrinsic defects or the absence of such impurities at all. Solving this problem is possible by using the method of radiation technologies [8]-[10]. This way, the formation of radiation defects in solids in the integrated combination with other effects such as temperature, mechanical load, the presence of an external electric and magnetic field, and the illumination allow purposefully regulating by the properties of solid-state materials. As it is known [11]-[14], the defects in silicon caused due to irradiation can play a role of various active centres (donors or acceptors that change the concentration of charge carriers and the position of the Fermi level, scattering and recombination centres that affect the electron and hole mobility, life time of non-equilibrium charge carriers). Radiation changes of the electrophysical properties of silicon practically for all temperatures are determined by secondary defects (complexes of vacancies and interstitial atoms with each other, with atoms of chemical impurities) or clusters of defects [12], [14]. Since the basic properties of silicon are strongly dependent on the presence of the defective structure, this, in turn, will have an impact on the parameters of the finished devices manufactured on its basis, such as sensitivity, current amplification factor, response time, stability, selectivity, dark current, etc. [15]-[17]. Designing and modelling on the basis of silicon of the radiation-resistant pressure sensors, which are used in the aerospace, rocket and space industries, thermonuclear and nuclear energy [18][20], and of the strained heterostructures, which can be applied in the fields of high radiation [21]-[23], require the detailed research of the impact of radiation irradiation and deformation on the electrical properties of silicon. In most of the works, only the effect of radiation or deformation on the physical properties of silicon single crystals has been considered. But integrated investigations of the effect of radiation and deformation on the electron transfer phenomena in silicon have not practically been carried out. Therefore, in this paper, the impact of high-energy electron irradiation on the electrical properties of uniaxially deformed single crystals $\mathrm{n}-\mathrm{Si}$ is investigated.

\section{EXPERIMENTAL RESULTS}

The investigated silicon single crystals with a resistivity of $0.25 \Omega \cdot \mathrm{cm}$, doped with an impurity of phosphorus, concentration of $N_{d}=2.2 \cdot 10^{16} \mathrm{~cm}^{-3}$, were grown at the Department for Development and Fluctuation Analysis of Semiconductor Materials and Structures of the V.E. Lashkaryov Institute of Semiconductor Physics, NAS of Ukraine. Samples of such silicon single crystals were irradiated by the electron flow $\Omega=1 \cdot 10^{17} \mathrm{el} . / \mathrm{cm}^{2}$ with energy of $12 \mathrm{MeV}$. Silicon single crystals were irradiated at room temperature at the microtron $\mathrm{M}-30$, whose parameters make it possible to form the beams of accelerated electrons with energies in the range of 1-25 MeV with monoenergy of $0.02 \%$ and current of up to $50 \mu \mathrm{A}$. Temperature control was executed using a copper-constantan differential thermocouple. During the irradiation, 
temperature of the silicon samples was regulated by blowing with vapours of liquid nitrogen. We measured the temperature dependencies of the Hall constant and the electrical conductivity for uniaxially deformed n-Si single crystals irradiated by the electrons. Uniaxial deformation and electric current through the silicon sample were directed along crystallographic directions [100] and [111]. Silicon samples for such research were cut in the form of rectangular parallelepipeds, $0.8 \cdot 0.8 \cdot 10 \mathrm{~mm}$ in size.

After appropriate preparation, the investigated sample was immovably fixed in brass pins using epoxy resin and placed in a thick-walled stainless steel tube. A small slot was made in the tube for output of the conductors, soldered to the current and Hall contacts of the sample. From below, the sample was supported by the pillar, which was a ceramic cork held by the corkscrew propeller. The tube was vertically attached to the casing with the help of the steel collet, which was installed in the casing. The volume hollow cylinder carried the main load containing a tube in a fixed vertical position. The upper surface of this cylinder had a thread tightened on the tube, and the lower one rested on the casing. A mechanical load was applied to the sample using a ceramic tube, which was inserted into a thick-walled stainless steel tube. A steel rod rested on the ceramic tube. The force was transferred to the steel rod and respectively to the ceramic tube and the investigated sample using the horizontally located lever. A pressure sensor, which was a spring attached to the lever, was used for creation of the mechanical load on the sample. The spring was calibrated in such a way that the certain magnitude of stretching, which was fixed by the vertically posted scale, corresponded to some value of the pressure force on the sample. A reservoir, into which water was served through a tap, was attached to the bottom of the spring. Due to the filling of the reservoir with water, the spring was stretched and the pressure on the sample was increased. The load was removed from the sample by opening the electric valve of the reservoir, which led to the leakage of water and reduced its mass in the reservoir.

Uniaxially deformed sample that was in a thick-walled tube was placed between the poles of the electromagnet, which allowed for a smooth change in the magnetic field within the range from 0 to $0.6 \mathrm{~T}$. The investigated sample was blowing with vapours of liquid nitrogen. The temperature control of samples was carried out also using a copper-constantan differential thermocouple. During the experiment, the accuracy of the measurement of temperature was $\pm 1 \mathrm{~K}$. The measurement error of Hall mobility did not exceed $8 \%$, and the concentration $-13 \%$.

In the previous paper [24], on the basis of measurements of infrared Fourier spectroscopy and the Hall effect, the nature and concentration of the main types of radiation defects formed in silicon single crystals under such conditions of irradiation were determined. It was shown that the main radiation defects were A-centres $\left(\mathrm{VO}_{i}\right.$ complexes), A-centres, modified with impurity of phosphorus ( $\mathrm{VO}_{\mathrm{i}} \mathrm{P}$ complexes) and complexes containing interstitial carbon $\left(\mathrm{C}_{\mathrm{i}} \mathrm{O}_{\mathrm{i}}\right.$ complexes).

In order to study the effect of these defects on the electrical properties of uniaxially deformed n-Si single crystals, the authors conducted the research of the piezo-Hall effect at the uniaxial pressures along crystallographic directions [100] and [111] for unirradiated and irradiated samples of silicon.

Figures 1 and 2 present the temperature dependencies of the Hall mobility for unirradiated n-Si single crystals under condition of uniaxial pressure along 
crystallographic directions [100] and [111]. As it is well known [25], in silicon single crystals at uniaxial pressure along the crystallographic direction [100] there will be deformation redistribution of electrons between two minima of the conduction band with low mobility, which descend down, and four minima with high mobility, which ascend up on the energy scale. This explains the decrease in the Hall mobility of electrons along with the increasing magnitude of the uniaxial pressure (Fig. 1).

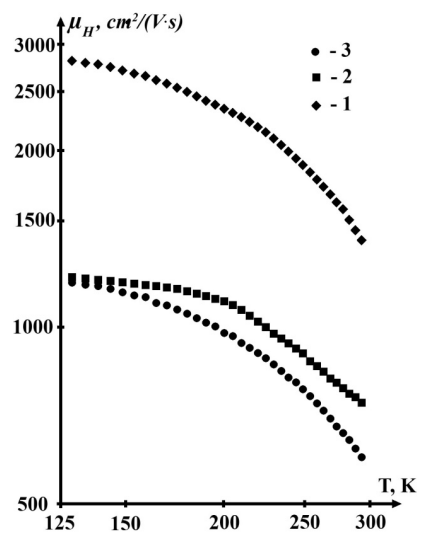

Fig. 1. Temperature dependencies of the Hall mobility for $\mathrm{n}-\mathrm{Si}<\mathrm{P}>$ single crystals at different values of the uniaxial pressure along the crystallographic direction [100]: 1-0 GPa; 2-0.42 GPa; 3-0.83 GPa.

Reduction of the Hall mobility with the increasing temperature is due to the increasing role of electron scattering on optical phonons, which are responsible for the intervalley scattering of electrons in silicon [26]. Detailed investigations of the tensoresistence of $\mathrm{n}-\mathrm{Si}$ at uniaxial pressure along the crystallographic direction [111] showed that resistivity increased along with a decrease in the electron mobility by increasing the effective mass of electrons at transformation of a two-axis isoenergetic ellipsoid of rotation in the three axes [27]. The increase in the magnitude of tensoresistence of silicon with the increasing temperature in these conditions is explained by the deformation non-parabolicity of the silicon conduction band, which occurs by removing the degeneracy of the zones $\Delta_{1}$ and $\Delta_{2}$ at the point $\mathrm{X}_{1}$ at the edge of the Brillouin zone [27]. These reasons explain the decrease in the Hall mobility of electrons with the increasing magnitude of the uniaxial pressure (Fig. 2).

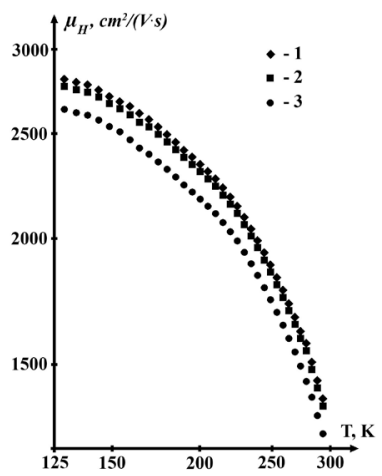

Fig. 2. Temperature dependencies of the Hall mobility for $\mathrm{n}-\mathrm{Si}<\mathrm{P}>$ single crystals at different values of the uniaxial pressure along the crystallographic direction [111]: 1-0 GPa; $2-0.37 \mathrm{GPa} ; 3-0.74 \mathrm{GPa}$. 
For n-Si single crystals, irradiated by the electrons (see Figs. 3 and 4), the Hall mobility of electrons increases and, reaching its maximum, decreases with the increasing temperature.

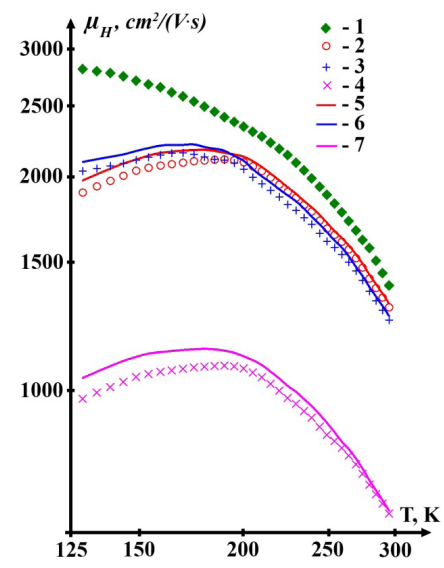

Fig. 3. Temperature dependencies of the Hall mobility for the irradiated $\mathrm{n}-\mathrm{Si}<\mathrm{P}>$ single crystals at different values of the uniaxial pressure along the crystallographic direction [100]: 1-0 GPa (unirradiated sample), 2-0 GPa, 3-0.42 GPa, 4-0.83 GPa. Solid curves are theoretical calculations on the basis of expression (14): 5-0 GPa, 6-0.42 GPa, 7-0.83 GPa.

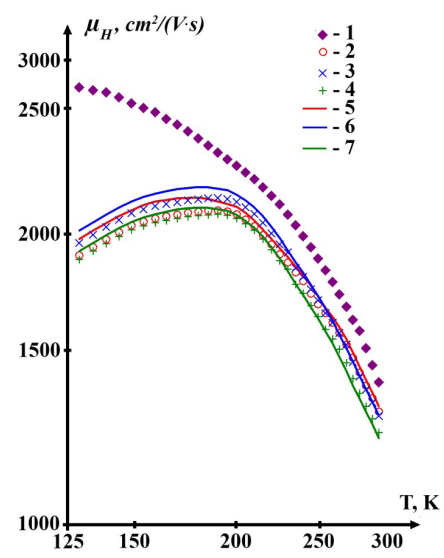

Fig. 4. Temperature dependencies of the Hall mobility for the irradiated $\mathrm{n}-\mathrm{Si}<\mathrm{P}>$ single crystals at different values of the uniaxial pressure along the crystallographic direction [111]: 1-0 GPa (unirradiated sample), 2-0 GPa, 3-0.37 GPa, 4-0.74 GPa. Solid curves are theoretical calculations on the basis of expression (18): 5-0 GPa, 6-0.37 GPa, 7-0.74 GPa.

The growth of the Hall mobility of electrons for undeformed and uniaxially deformed $\mathrm{n}$-Ge single crystals, irradiated by electrons, was explained by the decreasing resistivity gradients due to a decrease in the amplitude of the large-scale potential with the increasing temperature and deformation and also the concentration of charged radiation defects that were the active centres of scattering [28].

The concentration of electrons in the conduction band of irradiated n-Si single crystals was determined on the basis of the piezo-Hall effect measurements at the uniaxial pressures along the crystallographic directions [100] and [111] (Fig. 5). 


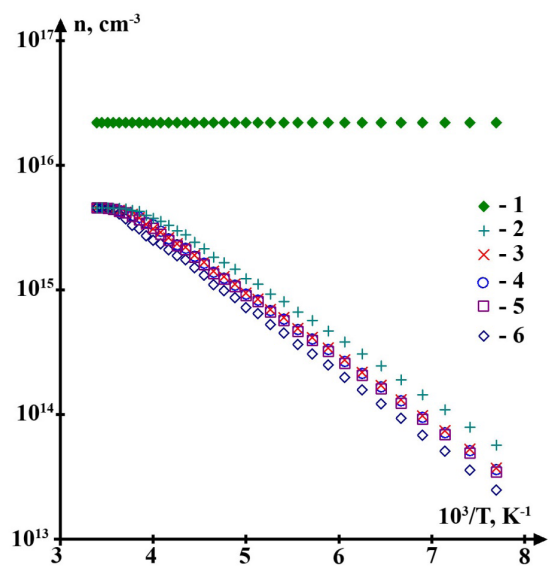

Fig. 5. Temperature dependencies of the concentration of electrons for the irradiated $\mathrm{n}-\mathrm{Si}<\mathrm{P}>$ single crystals at different values of the uniaxial pressure along the crystallographic directions [100] and [111]: 1-0 GPa (unirradiated sample), 2-0.83 GPa ([100]), 3-0.74 GPa ([111]), 4-0.37 GPa ([111]), 5-0.42 GPa ([100]), 6-0 GPa.

According to the data in Fig. 5, the concentration of electrons does not depend on the temperature for the unirradiated single crystals $\mathrm{n}-\mathrm{Si}$ (both in the absence and in the presence of the uniaxial deformation). This is explained by the fact that the phosphorus shallow donors will be fully ionized for the investigated range of temperatures. The deep energy levels $E_{C}-0.17 \mathrm{eV}$ and $E_{C}-0.107 \mathrm{eV}$, which belong to $\mathrm{VO}_{\mathrm{i}}$ and $\mathrm{VO}_{\mathrm{i}} \mathrm{P}$ complexes respectively [24], will be ionized only partially for the irradiated single crystals $\mathrm{n}-\mathrm{Si}$. The growth electron concentration with the increasing magnitude of the uniaxial pressure along the crystallographic direction [100] (Fig. 5 , curves 2 and 5) can be explained with a decrease in the ionization energy of these complexes under the deformation [24], [25]. Only marginal increase in the electron concentration in the conduction band of silicon is observed at uniaxial pressures along the crystallographic direction [111] (Fig. 5, curves 3 and 4). In this case, the activation energy of the main radiation defects, belonging to the $\mathrm{VO}_{\mathrm{i}} \mathrm{P}$ complexes, decreases slightly and at $P>0.4 \mathrm{GPa}$ does not depend on the magnitude of uniaxial pressure [24].

\section{THEORETICAL CALCULATIONS}

To interpret the obtained temperature dependencies of Hall mobility of electrons for silicon samples, irradiated by the flux of electrons $\Omega=1 \cdot 10^{17} \mathrm{el} . / \mathrm{cm}^{2}$ with the energy of $12 \mathrm{MeV}$ at uniaxial pressures along crystallographic directions [100] and [111], we write the expression for the Hall mobility under condition of the scattering of electrons on the large-scale potential [28]:

$$
\mu_{H}=\mu_{0} A \exp \left(-\frac{\Delta}{k T}\right),
$$

where $\mu_{0}-$ drift mobility of electrons for homogeneous material, $A-$ the Hallfactor, $\Delta-$ the amplitude of the large-scale potential. 


$$
\Delta=\frac{q^{2} N^{2 / 3}}{\varepsilon \cdot n^{1 / 3}}
$$

where $N$ - the concentration of charged defects, which is equal to the sum of concentrations of the ionized donors $N_{d}$ and compensating charged acceptors $N_{a}, \varepsilon-$ the dielectric penetration, $n$ - the concentration of electrons in the conduction band, $q$ - the charge of an electron.

Electron scattering on the ions of phosphorus impurity, acoustic phonons and optical phonons responsible for the intervalley scattering of electrons in silicon was taken into account at the calculations of the drift mobility of the electrons and the Hall factor. Mobility of charge carriers for any direction of isoenergetic surface, which is an ellipsoid of rotation, can be determined from the ratio [28]:

$$
\mu=\mu_{\perp} \sin ^{2} \theta+\mu_{\|} \cos ^{2} \theta
$$

where $\theta$ - the angle between the considered direction and the main axis of ellipsoid; $\mu_{\perp}$ and $\mu_{\|}$are the mobility of charge carriers across and along the axis of the ellipsoid, respectively.

In accordance with (3), for undeformed n-Si single crystals

$$
\mu_{0}=\frac{1}{3} \mu_{\|}+\frac{2}{3} \mu_{\perp}
$$

Under uniaxial pressure along the crystallographic direction [100], two minima of silicon conduction band will descend on the energy scale by a value [24]:

$$
\Delta E_{1}=-\left(\Xi_{d}+\frac{1}{3} \Xi_{u}\right)\left(S_{11}+2 S_{12}\right) P-\frac{2}{3} \Xi_{u}\left(S_{11}-S_{12}\right) P,
$$

and the other four minima will ascend by a value:

$$
\Delta E_{2}=-\left(\Xi_{d}+\frac{1}{3} \Xi_{u}\right)\left(S_{11}+2 S_{12}\right) P+\frac{1}{3} \Xi_{u}\left(S_{11}-S_{12}\right) P .
$$

If $n_{1}$ is the electron concentration in descending minima, and $n_{2}-$ in four minima which ascend at uniaxial pressure, then the total electron concentration in the conduction band of silicon is the following:

$$
n=n_{1}+n_{2} \text {. }
$$

For the non-degenerate electron gas:

$$
n_{1}=2\left(\frac{2 \pi m_{1} k T}{\hbar^{2}}\right)^{3 / 2} e^{\frac{E_{F}-\Delta E_{1}}{k T}}, n_{2}=2\left(\frac{2 \pi m_{2} k T}{\hbar^{2}}\right)^{3 / 2} e^{\frac{E_{F}-\Delta E_{2}}{k T}}
$$


Then

$$
\frac{n_{2}}{n_{1}}=\left(\frac{m_{2}}{m_{1}}\right)^{3 / 2} e^{\frac{\Delta E_{1}-\Delta E_{2}}{k T}}=B,
$$

where $m_{1}=2^{\frac{2}{3}}\left(m_{\|} m_{\perp}^{2}\right)^{\frac{1}{3}}$ and $m_{2}=4^{\frac{2}{3}}\left(m_{\|} m_{\perp}^{2}\right)^{\frac{1}{3}}$ are the effective mass of the density of states for these minima. Taking into account the value of the components of the effective mass tensor $m_{\|}=0.9163 m_{0}$ and $m_{\perp}=0.1905 m_{0}$ for electrons in silicon, $m_{1}=0.51 m_{0}$ and $m_{2}=0.81 m_{0}$ were obtained.

From expressions (7) and (9), we find that

$$
n_{1}=\frac{n}{B+1}, n_{2}=\frac{B n}{B+1} \text {. }
$$

According to (3), mobility of electrons in silicon at the uniaxial pressure along crystallographic direction [100] in the two descending minima is equal to:

$$
\mu_{1}=\mu_{\|},
$$

and for the four minima, which ascend on the energy scale,

$$
\mu_{2}=\mu_{\perp}
$$

Then for an arbitrary value of the uniaxial pressure $P$, the conductivity $\mathrm{n}-\mathrm{Si}$ is the following:

$$
\sigma_{P}=q n \mu=q\left(n_{1} \mu_{1}+n_{2} \mu_{2}\right) .
$$

Taking into account expressions (10) and (13), electron mobility at the uniaxial pressure $\mathrm{n}-\mathrm{Si}$ along the crystallographic direction [100] is equal to

$$
\mu_{0}=\frac{\mu_{1}+B \mu_{2}}{B+1}
$$

The intervalley scattering of electrons on optical phonons is described by the scalar relaxation time [29]. As shown in research [26], intervalley scattering in the silicon is caused by the interaction of electrons with optical phonons at characteristic temperatures $T_{C l}=190 \mathrm{~K}$ and $T_{C 2}=630 \mathrm{~K}$. The constants of the optical deformation potential for these phonons $\Xi_{190}=1.8 \cdot 10^{8} \mathrm{eV} / \mathrm{cm}$ and $\Xi_{630}=4 \cdot 10^{8} \mathrm{eV} / \mathrm{cm}$ were found in the studies. The values of the constants of the acoustic deformation potential $\Xi_{u}=9.23 \mathrm{eV}$ and $\Xi_{d}=2.12 \mathrm{eV}$ are given in work [30]. Then, in the most general case of electron scattering on the impurity ions, acoustic phonons and optical phonons responsible for intervalley scattering, the expressions for the components of the relaxation time tensor can be written as follows [29]: 


$$
\frac{1}{\tau_{\mid}}=\frac{1}{\tau_{\mid}^{a, i}}+\frac{1}{\tau_{1}}+\frac{1}{\tau_{2}} ; \frac{1}{\tau_{\perp}}=\frac{1}{\tau_{\perp}^{a, i}}+\frac{1}{\tau_{1}}+\frac{1}{\tau_{2}},
$$

where $\tau_{\mid}^{a, i}, \tau_{\perp}^{a, i}$ are the longitudinal and transverse components of the relaxation time tensor for scattering on acoustic phonons and impurity ions, respectively; $\tau_{1}, \tau_{2}$ are the relaxation times for intervalley scattering on optical phonons at characteristic temperatures $T_{C l}=190 \mathrm{~K}$ and $T_{C 2}=630 \mathrm{~K}$.

In the case of uniaxial pressure along the crystallographic direction [111], an expression for the components of the effective mass tensor will be as follows [27]:

$$
m_{11}=\frac{m_{\perp}}{1+\gamma P}, m_{22}=\frac{m_{\perp}}{1-\gamma P}, m_{33}=m_{\|}
$$

where $\gamma=6.74 \cdot 10^{-11} \mathrm{~Pa}^{-1}$.

The deformation non-parabolicity of the conduction band of silicon, which explains the nonlinear growth of the tensoresistence and the dependence of tensoresistence on temperature for such uniaxial pressure, can be represented as follows [27]:

$$
\varepsilon(P)=\varepsilon(1+\lambda \varepsilon)=\frac{\hbar^{2}}{2}\left(\frac{k_{1}^{2}}{m_{11}}+\frac{k_{2}^{2}}{m_{22}}+\frac{k_{3}^{2}}{m_{33}}\right),
$$

where $\lambda=\lambda_{0} P^{2}$ is non-parabolicity parameters, $\lambda_{0}=20 \frac{\mathrm{m}^{3}}{\mathrm{~N}^{3}}$.

In this case, the mobility for uniaxialy deformed silicon is equal to:

$$
\begin{aligned}
& \mu_{0}=\frac{1}{3}\left(\mu_{11}+\mu_{22}+\mu_{33}\right) . \\
& \mu_{11}=\frac{q}{m_{11}}<\tau_{11}>, \mu_{22}=\frac{q}{m_{22}}<\tau_{22}>, \mu_{33}=\frac{q}{m_{33}}<\tau_{33}>.
\end{aligned}
$$

It is necessary to replace the variable $x=\frac{\varepsilon}{k T}$ with $x_{1}=x+\lambda k T x^{2}$ in the calculations of these mobility components.

Figures 3 and 4 (solid curves) present the theoretical calculations of the Hall mobility of electrons for irradiated n-Si single crystals, on the basis of expressions (14) and (18), under condition of electron scattering on phosphorus impurity ions, acoustic phonons and optical phonons responsible for intervalley scattering.

\section{DISCUSSION OF THE OBTAINED RESULTS}

From the analysis performed, it follows that for irradiated n-Si single crystals, Hall mobility with the increasing temperature initially increases and decreases during the crossing of the maximum. The growth of Hall mobility can be explained by two 
reasons: 1) by decreasing of the amplitude of a large-scale potential with an increase of the electron concentration in the silicon conduction band due to the growth of temperature or deformation; 2) by decreasing of the concentration of charged defects belonging to the $\mathrm{VO}_{\mathrm{i}} \mathrm{P}$ and $\mathrm{VO}_{\mathrm{i}}$ complexes, and, accordingly, the probability of scattering on such defects with the increasing temperature and uniaxial pressure. These reasons explain the growth of the magnitude of Hall electron mobility for the uniaxially deformed $\mathrm{n}$-Si single crystals with an increase in the magnitude of uniaxial pressure to $0.42 \mathrm{GPa}$ (Fig. 3, curve 3) and $0.37 \mathrm{GPa}$ (Fig. 4, curve 3 ) at low temperatures. The decrease in the Hall mobility during the crossing of the maximum is due to the growing probability of intervalley scattering of electrons on the optical phonons with an increase in temperature. For such temperatures, the Hall mobility of electrons, as in the case of unirradiated silicon single crystals, decreases with an increase in the magnitude of uniaxial pressure. The slight difference between the obtained experimental results and the corresponding theoretical calculations is due to the fact that the relaxation time for electron scattering on the created radiation defects was not taken into account during the construction of the theoretical model of the Hall electron mobility for irradiated n-Si single crystals. Since radiation defects, as a rule, create deep energy levels in the band gap of a semiconductor and their microstructure is difficult to establish in many cases, it is a difficult task to simulate the potential of the interaction of an electron with such defects. Today, solving such problems is based on the creation of semi-empirical models of radiation defects, which often do not allow interpreting the obtained experimental results. However, the proposed theoretical model allows qualitatively and at certain temperatures quantitatively explaining the features of the temperature dependencies of the Hall mobility for the undeformed and uniaxially deformed n-Si single crystals with radiation defects.

\section{CONCLUSIONS}

The obtained experimental results and theoretical calculations show that for uniaxially deformed n-Si single crystals along crystallographic directions [100] and [111], irradiated by high-energy electrons, a decrease in a large-scale potential under the increase of temperature or magnitude of uniaxial pressure causes growth of the Hall mobility. Hall mobility of electrons for irradiated n-Si single crystals at the investigated temperatures and uniaxial pressures is determined by different relative contribution of the mechanisms of electron scattering on optical phonons, which are responsible for intervalley scattering, ions of phosphorus shallow impurities and largescale potential. The results can be used for constructing, on the basis of n-Si single crystals of various electronic devices and sensors, strained silicon nanostructures (Si-quantum dots and quantum wells, heterostructures $\mathrm{SiGe}$ ), which can be applied in the fields of high radiation and deformation. The presented theoretical model for calculating the Hall mobility of electrons for irradiated n-Si single crystals can be useful in modelling the electrical properties of other many-valley semiconductors with radiation defects, the presence of which leads to the emergence of large-scale potential. 


\section{REFERENCES}

1. Yang, W., Chen, J., Zhang, Y., Zhang, Y., He, J. H., \& Fang, X. (2019). Silicon-compatible Photodetectors: Trends to Monolithically Integrate Photosensors with Chip Technology. Advanced Functional Materials, 29(18), 1808182. DOI: 10.1002/adfm.201808182.

2. Goley, P. S., \& Cressler, J. D. (2019). Silicon-Based Electronic Photonic Integrated Circuits: Resiliency in the Space Environment. Georgia Institute of Technology Atlanta United States, 220-223. Available at https://apps.dtic.mil/dtic/tr/fulltext/u2/1075341.pdf

3. Zhanshe, G., Fucheng, C., Boyu, L., Le, C., Chao, L., \& Ke, S. (2015). Research Development of Silicon MEMS Gyroscopes: A Review. Microsystem Technologies, 21(10), 2053-2066. DOI: 10.1007/s00542-015-2645-x.

4. Qin, Y., Howlader, M., \& Deen, M. (2015). Low-temperature Bonding for Siliconbased Micro-optical Systems. Photonics, 2(4), 1164-1201. Multidisciplinary Digital Publishing Institute. DOI: 10.3390/photonics2041164.

5. Sharma, V., \& Rajawat, A. (2018). Review of Approaches for Radiation Hardened Combinational Logic in CMOS Silicon Technology. IETE Technical Review, 35(6), 562-573. DOI: 10.1080/02564602.2017.1343689

6. Nalwa, H. S. (ed.). (2001). Silicon-based material and devices, two-volume set: materials and processing, properties and devices 1. Academic Press.

7. Shimura, F. (ed.). (2012). Semiconductor silicon crystal technology. Elsevier Science \& Technology.

8. Sun, Y., \& Chmielewski, A. G. (eds.). (2017). Applications of ionizing radiation in materials processing. Institute of Nuclear Chemistry and Technology.

9. Gradoboev, A. V., \& Simonova, A. V. (2017). Radiation Technologies in the Production of Semiconductor Devices. In IX International Scientific and Practical Conference "Physical and Technical Problems in Science, Industry and Medicine", 21-22 September 2017. Tomsk: TPU Publishing House.

10. Lee, B.J., Zhang, Z.M., Early, E.A., DeWitt, D.P., \& Tsai, B.K. (2004). Modeling the Radiative Properties of Silicon with Thin-Film Coatings and the Experimental Validation. In 37th AIAA Therm Conf., 28 June-1 July 2004. Portland: OR.

11. Pagava, T. A., \& Maisuradze, N. I. (2010). Anomalous Scattering of Electrons in n-Si Crystals Irradiated with Protons. Semiconductors, 44(2), 151-154. DOI: 10.1134/ S1063782610020041.

12. Gaidar, G. P. (2015). On the Tensoresistance of n-Ge and n-Si Crystals with Radiation-Induced Defects. Semiconductors, 49(9), 1129-1133. DOI: 10.1134/ S1063782615090110.

13. Funtikov, Y. V., Dubov, L. Y., Shtotsky, Y. V., \& Stepanov, S. V. (2016). RadiationInduced Defects in Si after High Dose Proton Irradiation. Defect and Diffusion Forum, 373, 209-212. Trans Tech Publications. DOI: 10.4028/www.scientific.net/DDF.373.209.

14. Yeritsyan, H. N., Sahakyan, A. A., Grigoryan, N. E., Harutyunyan, V. V., Grigoryan, B. A., Amatuni, G. A., \& Rhodes, C. J. (2018). The Use of Different Pulsed Electron Irradiation for the Formation of Radiation Defects in Silicon Crystals. Journal of Electronic Materials, 47(7), 4010-4015. DOI: 10.1007/s11664-018-6286-6.

15. 15. Ciurea, M. L. (2013). Effect of Stress on Trapping Phenomena in Silicon: from Single Crystal to Nanostructures. Romanian Reports in Physics, 65(3), 841-856.

16. Ding, L., Gerardin, S., Paccagnella, A., Gnani, E., Bagatin, M., Driussi, F., \& Le Royer, C. (2015). Effects of Electrical Stress and Ionizing Radiation on Si-based TFETs. In EUROSOI-ULIS 2015: 2015 Joint International EUROSOI Workshop and International Conference on Ultimate Integration on Silicon, January 2015 (pp. 137-140). IEEE. Available at https://ieeexplore.ieee.org/document/7063792. 
17. Momot, I., Malygina, H., Bertini, O., Heuser, J., Sturm, C., Teklishyn, M., \& Lymanets, A. (2017). Studies of Radiation Field Impact on Microstrip Sensors for the CBM Silicon Tracking System. Verhandlungen der Deutschen Physikalischen Gesellschaft, 49(44), 1.

18. Holbert, K. E., Nessel, J. A., McCready, S. S., Heger, A. S., \& Harlow, T. H. (2003). Response of Piezoresistive MEMS Accelerometers and Pressure Transducers to High Gamma Dose. IEEE Transactions on Nuclear Science, 50(6), 1852-1859. Available at https://ieeexplore.ieee.org/document/1263811.

19. Marinaro, D. G., McMahon, P., \& Wilson, A. (2008). Proton Radiation Effects on MEMS Silicon Strain Gauges. IEEE Transactions on Nuclear Science, 55(3), 1714-1718. Available at https://ieeexplore.iee.org/document/4545162.

20. Vlasov, A.I., Mileshin, S., Tsivinskaya, T.A., \& Shakhnov, V.A. (2018). Radiation Resistance of MEMS Sensors and Methods of Its Estimation. Problems of Perspective Micro- and Nanoelectronic Systems Development, 4, 190-196.

21. Sobolev, N. A. (2013). Radiation Effects in Si-Ge Quantum Size Structure. Semiconductors, 47(2), 217-227. DOI: 10.1134/S1063782613020188.

22. Hao, M., Hu, H., Liao, C., \& Wang, B. (2017). Effects of Gamma-Ray Radiation on Channel Current of the Uniaxial Strained Si Nano-scale NMOSFET. IEICE Electronics Express, 14(19), 20170866-20170866. DOI: 10.1587/elex.14.20170866.

23. Hao, M., Hu, H., Liao, C., Kang, H., Su, H., Zhang, Q., \& Zhao, Y. (2017). Total Ionizing Dose Radiation Effect on the Threshold Voltage for the Uniaxial Strained Si Nano NMOSFET. IEICE Electronics Express, 14-20170411. DOI: 10.1587/elex.14.20170411.

24. Luniov, S., Zimych, A., Khvyshchun, M., Yevsiuk, M., \& Maslyuk, V. (2018). Specific Features of Defect Formation in the nSi. Eastern-European Journal of Enterprise Technologies, 6(12), 35-42. DOI: 10.15587/1729-4061.2018.150959.

25. Fedosov, A. V., Luniov, S. V., \& Fedosov, S. A. (2011). Influence of Uniaxial Deformation on the Filling of the Level Associated with A-Center in n-Si Crystals. Ukrainian Journal of Physics, 56(1), 69-73. Available at http://archive.ujp.bitp.kiev.ua/files/ journals/56/1/560108p.pdf.

26. Fedosov, A. V., Luniov, S. V., \& Fedosov, S. A. (2010). Specific Features of Intervalley Scattering of Charge Carriers in n-Si at High Temperatures. Semiconductors, 44(10), 1263-1265. DOI: 10.1134/S1063782610100039.

27. Baranskii, P. I., Kolomoets, V. V., \& Korolyuk, S. S. (1983). The Non-parabolicity of the n-Si Conduction Band Caused by Elastic Deformation along the [111] Direction. Physica Status Solidi (b), 116(2), K109-K112. DOI: 10.1002/pssb.2221160241.

28. Luniov, S. V., Zimych, A. I., Nazarchuk, P. F., Maslyuk, V. T., \& Megela, I. G. (2016). Specific Features of Electron Scattering in Uniaxially Deformed n-Ge Single Crystals in the Presence of Radiation Defects. Radiation Effects and Defects in Solids, 171(11-12), 855-868. DOI: 10.1080/10420150.2016.1250094.

29. Luniov, S. V., Burban, O. V., \& Nazarchuk, P. F. (2015). Electron Scattering in the $\Delta_{1}$ Model of the Conduction Band of Germanium Single Crystals. Semiconductors, 49(5), 574-578. DOI: 10.1134/S1063782615050140.

30. Luniov, S. V., Panasiuk, L. I., \& Fedosov, S. A. (2012). Deformation Potential Constants $\Xi_{\mathrm{u}}$ and $\Xi_{\mathrm{d}}$ in n-Si Determined with the Use of the Tensoresistance Effect. Ukrainian Journal of Physics, 57(6), 636-641. Available at http://archive.ujp.bitp.kiev.ua/files/ journals/57/6/570608p.pdf 


\title{
ELEKTRONU IZKLIEDĒJUMA MEHĀNISMI VIENASS DEFORMĒTOS ATSEVIŠKOS SILIKONA KRISTĀLOS AR RADIĀCIJAS DEFEKTIEM
}

\author{
S.V. Luniovs, V.V. Lišuks, V.T. Masḷuks, O.V. Burbans
}

Kopsavilkums

Aprakstīi elektronu Holla mobilitātes temperatūras atkarības mērījumi vienass deformētiem atsevišķiem n-Si kristāliem, ko izstaro elektronu plūsma $\Omega=1 \cdot 10^{17} \mathrm{el}$./ $\mathrm{cm}^{2}$ ar enerğiju $12 \mathrm{MeV}$ iegūti, balstoties uz piezo-Holla efekta mērījumiem. No šo mērìjumu analīzes izriet, ka pie vienass spiediena (0-0.42) GPa un (0-0.37) GPa kristalogrāiskajos virzienos ir novērojams deformāciju ierosināts Holla mobilitātes pieaugums. Balstoties uz piedāvāto mobilitātes teorētisko modeli, šis pieaugums ir izskaidrojams ar liela mēroga potenciāla amplitūdas samazināšanos, vienass deformāciju magnitūdas palielināšanos un attiecīgi iespējamu elektronu izkliedējumu.

20.09.2019. 